\title{
O backlash e a construção do ethos discursivo da mulher
}

\author{
The backlash and the construction of the woman's discursive ethos
}

Elaine Cristina Fonseca

Universidade Federal de Minas Gerais, Belo Horizonte, Minas Gerais, Brasil.

$$
\diamond
$$

\begin{abstract}
Resumo: O presente trabalho tem por objetivo a realização de uma análise retóricoargumentativa comparativa entre duas reportagens jornalísticas, publicadas em dois veículos diversos, que noticiam e divulgam uma mesma pesquisa científica. Pretendemos identificar as diversas estratégias argumentativas utilizadas em ambas as reportagens na construção de um ethos discursivo da mulher contemporânea, fazendo uso das três provas retóricas - ethos, pathos e $\log o s$ - na esteira dos estudos desenvolvidos por Amossy (2005, 2011), Charaudeau (2008) e Galinari $(2012,2014)$. Também pretendemos relacionar esse ethos discursivo ao conceito de backlash, tal como utilizado por Faludi (2001). Nessa concepção, o backlash é compreendido como um discurso reacionário à emancipação feminina ocorrida nas últimas décadas. As análises presentes neste artigo são provenientes de um recorte de nossa dissertação de mestrado.

Palavras-chave: ethos discursivo; backlash; estratégias argumentativas.

Abstract: The present study aims to conduct a rhetoric argumentative comparative analysis between two newspaper reports, publicized in two different communication means, that publish and disclose the same scientific research. We intend to identify the various argumentative strategies used on both reports in the characterization of the contemporaneous woman, making use of the three rhetorical proofs - ethos, pathos and logos - in the wake of the studies developed by Amossy $(2005,2011)$, Charaudeau $(2008)$ and Galinari $(2012,2014)$. It's also intended to relate this discursive ethos to the concept of backlash, such as used by Faludi (2001). Within such conception, backlash is understood as a reactionary speech against the female emancipation arisen in the last decades. The analyses featured in the present article derive from an excerpt of our master's dissertation.
\end{abstract}

Keywords: discursive ethos; backlash; argumentative strategies.

\section{Considerações iniciais}

Nos últimos séculos, nossa sociedade ocidental tem experienciado diversas mudanças e revoluções em seus costumes. Durante todo esse tempo, as mídias de cada época, de cada espaço, têm tido um papel fundamental, sejam como refletoras ou como promulgadoras dos mais variados tipos de discursos, sendo eles favoráveis ou contrários a qualquer tipo de manifestação.

Um grande exemplo são as mudanças em relação ao papel social feminino ocorridas, principalmente, nas últimas décadas. Em nossa dissertação de mestrado, (FONSECA, 2016) pudemos identificar a relevância do papel das mídias como promulgadoras ou questionadoras de tais mudanças, desde as primeiras divulgações dos ideais feministas em meados do século XIX, passando pela criação midiática de um ethos negativo e grotesco das sufragistas do início do século XX até nossos dias atuais nos quais discursos de ideologias diversas disputam por espaço.

No ano de 1991, a jornalista norte-americana Susan Faludi lançou o livro Backlash - o contra ataque na guerra não declarada contra as mulheres, no qual denunciava todo um discurso reacionário presente nos mais diversos tipos de mídia, em uma espécie de reação negativa, conservadora, contra a luta por igualdade, equidade e os avanços femininos obtidos nas últimas décadas.

De acordo com esse discurso, com esse backlash, essa igualdade de direitos almejada acabara por trazer uma série de prejuízos sociais aos próprios sujeitos do sexo feminino, como certa infelicidade generalizada, certa "melancolia de gênero", o maior deles. 
Tendo em vista essa conceituação, encontramos duas reportagens jornalísticas de duas conhecidas revistas semanais, divulgadoras de uma pesquisa científica denominada "O Paradoxo do declínio da felicidade feminina", que poderiam vincular-se ao conceito de backlash, de acordo com Faludi (2001). A primeira delas, intitulada "Por que as mulheres são tão tristes?", foi divulgada pela revista Época em suas versões impressa e digital no mês de outubro do ano de 2009. A reportagem é assinada pela jornalista Martha Mendonça com colaboração de Fernanda Colavitti. Já a segunda reportagem, intitulada "O paradoxo da tristeza", foi divulgada também em ambas as versões no mês de Maio do ano seguinte, pela revista Veja, em uma edição especial dedicada às mulheres em virtude da comemoração do dia internacional da mulher. A reportagem é assinada por Betsey Stevenson, Justin Wolfers e Dwyer Gunn.

Cabe acrescentar que ambas as revistas possuem grande poder de influência na sociedade brasileira, por terem grande circulação e serem as duas revistas semanais com maiores tiragens e vendagens até o momento. $\mathrm{O}$ fato de contarem com versões digitais, além de versões impressas, aumenta ainda mais o alcance de ambos os veículos.

A nossa análise retórico-argumentativa das reportagens nortear-se-á pela identificação de um ethos da mulher contemporânea no discurso midiático brasileiro, buscando elementos comuns ou contrários ao backlash.

O artigo será dividido em três partes. Na primeira parte, apresentaremos uma breve revisão acerca da utilização atual do conceito de ethos e dos dois outros constituintes da tríade retórica: o logos e o pathos. Na segunda parte, faremos uma breve explanação e esclarecimentos acerca do conceito de backlash. Finalmente, na terceira parte, realizaremos uma análise das reportagens jornalísticas supracitadas, buscando identificar, através da utilização dos conceitos de ethos, pathos e logos, as estratégias argumentativas utilizadas e a construção de um ethos discursivo da mulher contemporânea que possa ser relacionado ao backlash.

\section{O backlash e a construção da imagem da mulher}

Em relação ao backlash, Faludi (2001) considera que a luta pela ampliação dos direitos femininos na sociedade contemporânea obteve seu auge em quatro diversos momentos históricos, todos eles seguidos por tempos de backlash, tempos de tentativas de retrocesso, sempre muito bem divulgados pelas mídias de cada época.

Dessa forma, o movimento feminista surgido em meados do século XIX, teria sofrido desde esse início com várias advertências e retaliações por parte de religiosos, intelectuais e, mesmo, especialistas médicos que alertavam as mulheres acerca da incompatibilidade feminina para a conciliação entre o domínio profissional/ público e o domínio familiar, o que ocasionaria perda da feminilidade, esgotamento nervoso, doenças mentais e físicas, epidemias de infertilidade, crises familiares, aumento no número de divórcios, diminuição no número de casamentos, infelicidade feminina, solidão. Algo semelhante ocorreu nas primeiras décadas do século XX, quando as sufragistas eram constantemente difamadas pela mídia, e também nas décadas de 1940 e 1950, no póssegunda guerra mundial, quando as mulheres europeias e norte-americanas que haviam assumido majoritariamente o mercado de trabalho, foram recrutadas "de volta para o lar", para que ex-soldados egressos pudessem reassumir seus cargos.

Já o backlash contemporâneo e atual, surgido ao longo da década de 1980, logo após a revolução sexual e de costumes experienciada nas duas décadas anteriores, funcionava e funciona em dois níveis. Segundo a autora, esse discurso, por um lado, "convencia as mulheres de que seus sentimentos de angústia e insatisfação eram resultado de certo excesso de independência", por outro lado, "buscava destruir, gradativamente, os mínimos avanços alcançados no trabalho, na política e na forma de pensar" (FALUDI, 2001, p. 01).

Seguindo essa concepção, podemos considerar que um ethos bastante propagado por grande parte das mídias seria, então, o de uma mulher contemporânea vítima de um "excesso de igualdade" que "nunca foi tão livre, mas em compensação, nunca se sentiu tão infeliz" (FALUDI, 2001, p. 09).

No entanto, o que Faludi questiona em sua obra é se a tal igualdade ou equidade feminina propagada já teria sido, de fato, alcançada, levando em conta diversos fatores sociais, econômicos e culturais, tais como: salários, em média, ainda desiguais; jornadas de trabalho duplas ou triplas; maior responsabilização pelos trabalhos domésticos e com os filhos (ainda que se trabalhe fora); assédio moral e sexual; falta de creches para os filhos; preconceitos diversos; culpabilização; violência domiciliar; violência sexual; entre outros problemas, que ainda seriam vivenciados por grande parte das mulheres.

$\mathrm{Na}$ esteira das questões denunciadas por Faludi (2001), realizaremos mais à frente a análise das reportagens jornalísticas já citadas, utilizando ainda, por suporte teórico, a retórica e seus meios de persuasão.

\section{Retórica e os meios de persuasão}

Aristóteles, em sua sistematização da Retórica no século IV a.C., na Grécia antiga, já havia classificado os meios de persuasão utilizados em uma argumentação 
em três diferentes tipos: o ethos - apelo que se valeria da credibilidade e do caráter do orador, o pathos - apelo direcionado às emoções do auditório e o logos - apelo direcionado à razão, quando o orador tentaria persuadir o auditório através da demonstração do que seria verdade ou do que pareceria ser verdade.

Séculos mais tarde, essa tríade retórica, aristotélica, ainda se mostra bastante pertinente nos processos de produção e análise dos mais variados tipos de discursos, sendo bastante utilizada, atualmente, nos campos do Direito, da Filosofia, da Análise do Discurso, dos Estudos da Argumentação, entre outros.

No âmbito da Análise do Discurso e dos Estudos da Argumentação, principalmente, algumas releituras vêm sendo feitas. Se na retórica de Aristóteles o ethos dizia respeito a uma imagem do orador criada, em sua totalidade, no momento de uma enunciação oral e baseada unicamente nas palavras proferidas ao longo de determinado discurso, nos dias de hoje, teóricos como Charaudeau (2008) e Amossy $(2005,2011)$ encontram-se alinhados a uma posição semelhante à de Platão, segundo a qual o ethos de um orador, aos olhos de seu auditório, seria constituído, em grande parte, por sua reputação, sua posição social na comunidade. Esse posicionamento foi também defendido pelo retórico ateniense Isócrates e pelo retórico romano Cícero. Nas palavras de Isócrates:

[...] note-se, o homem que deseja persuadir as pessoas não será negligente quanto à questão de caráter. Não, pelo contrário, ele se esforçará, sobretudo para estabelecer um nome mais honrado entre seus concidadãos; pois quem não sabe que as palavras trazem maior convicção quando faladas por homens íntegros e que o argumento que é baseado na vida de um homem é de mais peso do que o que é fornecido por palavras? (ISÓCRATES, 1980)

\section{E nas palavras de Cícero:}

\begin{abstract}
Tem muita força então, para que se vençam as causas que se aprovem o caráter, os costumes, os feitos e a vida dos que defendem as causas e daqueles em favor de quem as defendem. [...] Cativam-se os ânimos pela dignidade do homem, por seus feitos, por sua refutação (CÍCERO, 1942, p. 182).
\end{abstract}

Por outro lado, esses autores da atualidade citados, Amossy e Charaudeau, admitem também, com Aristóteles, a existência de um ethos discursivo - criado no momento de uma enunciação oral e/ou escrita. No entanto, ambos os autores também admitem a existência de um ethos prévio (AMOSSY, 2005, 2011) ou pré-discursivo (CHARAUDEAU, 2008), anterior a essa enunciação e baseado em conhecimentos prévios, representações socioculturais e estereótipos partilhados pelo auditório a respeito de seu enunciador:

Ora, para construir a imagem do sujeito que fala, esse outro se apoia ao mesmo tempo nos dados preexistentes ao discurso - o que ele sabe a priori do locutor $-\mathrm{e}$ nos dados trazidos pelo próprio ato de linguagem (CHARAUDEAU, 2008, p. 115).

Considerando esse ethos prévio e as posições sociais ocupada pelo enunciador, Amossy afirma que:
A posição institucional do orador e o grau de legitimidade que ela the confere contribuem para suscitar uma imagem prévia. Esse ethos pré-discursivo faz parte da bagagem dóxica dos interlocutores e é necessariamente mobilizado pelo enunciado em situação. Um nome, uma assinatura são suficientes para evocar uma representação estereotipada que é levada em conta no jogo especular da troca verbal. O ethos prévio ou pré-discursivo pode ser confirmado [...] ou modificado (AMOSSY, 2005, p. 137).

Acrescentamos, a partir daí que, durante e após o processo de enunciação, o ethos discursivo poderá corresponder ou não ao ethos prévio ou pré-discursivo que havia sido criado anteriormente pelo auditório.

Tratando agora da subdivisão dos meios de persuasão, uma releitura também atual é a de que, na prática, haveria uma imbricação natural entre ethos, pathos e logos como podemos observar em Galinari (2014). Para o autor, as três provas retóricas não seriam três categorias distintas e isoladas, mas dimensões do mesmo discurso, sendo o ethos e o pathos desdobramentos semântico-discursivos do logos.

Seguindo essa perspectiva de Galinari (2014), podemos investir em uma análise das relações intrínsecas entre os meios de persuasão na qual o apelo ao logos, por exemplo, poderia possibilitar a criação da imagem de seu enunciador ou de um terceiro elemento (o apelo ao ethos) ou seria capaz de suscitar emoções no auditório (apelo ao pathos) e vice-versa, entre diversas possibilidades, como poderemos verificar mais à frente em nossas análises.

Outra importante releitura atual acerca do conceito de ethos é sua utilização não somente na construção da imagem de um enunciador, através de seu próprio discurso, mas também na construção da imagem de uma terceira pessoa, de um outrem, ou de um determinado grupo social através do discurso de um enunciador.

Muitos dos analistas do discurso contemporâneos desconsideram o ethos de outrem, restringindo-se ao ethos do orador. Uma das exceções é Galinari (2012), que questiona a não inclusão do ethos de outrem pelos analistas do discurso e estudiosos da argumentação: 
[...] acredito que poderíamos construir análises discursivas destinadas a elucidar os "ethé de outrem", o que estenderia o ethos não apenas às imagens de si das instâncias de produção dos discursos abordados, mas também às imagens de seres/coisas ou instituições tematizados por esses mesmos discursos. O ethos, assim, não se resumiria, no plano teórico, ao conhecido jargão "imagens de si", mas se estenderia também ao que poderíamos chamar de "imagens de outrem". (GALINARI, 2012, p. 66)

Galinari esclarece que o próprio Aristóteles reconhece não só o ethos do orador, mas também o ethos de outrem, embora não o inclua em suas definições. Isso ocorre, quando o filósofo arrola, entre os genera causarum (gêneros retóricos), o gênero epidíctico e fica evidente que ele considera o "outrem", já que nesse gênero de discurso, embora participe o ethos do orador, o objetivo imediato é mostrar os ethé, virtuosos ou viciosos, das pessoas elogiadas (encômio) ou censuradas (invectiva). Cabe ressaltar que essa é a utilização do apelo ao ethos que utilizaremos, no presente trabalho, na análise de duas reportagens jornalísticas, uma veiculada pela revista Época e outra veiculada pela revista Veja.

\section{Análise de reportagens}

Analisando a reportagem jornalística intitulada "Por que as mulheres são tão tristes", veiculada pela revista Época em sua versão impressa e em sua versão digital no mês de Outubro do ano de 2009, constatamos a utilização do recurso do ethos, enquanto estratégia retórico-argumentativa, principalmente, através da construção da imagem, não do enunciador do discurso, mas de um outrem, a construção da imagem da mulher contemporânea. Para tanto, a autora da reportagem faz uso de um recurso que identificamos como uma espécie de "criação de personagens", recurso esse bastante utilizado em matérias jornalísticas, mas que, como veremos, não foi utilizado, por exemplo, na segunda reportagem analisada.

Trata-se da seleção de algumas pessoas para que essas sejam entrevistadas enquanto representantes do grupo social que está em discussão em determinada reportagem jornalística. Suas falas individuais, então, são tomadas como falas provenientes de toda uma classe, neste caso específico, trata-se de um grupo social constituído pelas mulheres contemporâneas.

Nessa reportagem, duas mulheres nos são apresentadas sob essas condições. A primeira delas, Cláudia Valli, surge logo no início do texto, no primeiro parágrafo, para sermos mais exatos. Já a segunda "personagem", Olga Torres, é apresentada no nono parágrafo da reportagem, na segunda página de sua versão digital.
Realizando uma análise comparativa e contrastiva entre essas duas "personagens da vida real", percebemos que ambas pertencem ao público leitor majoritário da revista Época: mulheres pertencentes à classe média alta (o que pode ser inferido por suas profissões: a primeira é redatora de televisão, enquanto a segunda é terapeuta corporal) e que têm mais de 35 anos de idade.

Segundo informações divulgadas pelo site eletrônico da revista Época, estima-se que $64 \%$ dos leitores da revista sejam pertencentes às chamadas classes sociais $\mathrm{A}$ e $\mathrm{B}$, classe alta e média alta, respectivamente e que $71 \%$ dos leitores tenha mais de vinte e cinco anos de idade.

A partir dessas informações, podemos inferir que a escolha dessas personagens não é arbitrária, uma vez que o fato de ambas possuírem características em comum com a maior parte do público leitor da revista possibilita a criação de um ethos discursivo da mulher contemporânea com a qual esse público se identifique. Chamou-nos a atenção, por exemplo, o fato de a empregada doméstica da casa de Cláudia Valli, por exemplo, ser somente mencionada no texto, mas não entrevistada, provavelmente por não fazer parte do perfil majoritário do auditório da revista. Essa exclusão, no entanto, acaba por deixar de fora um ponto de vista a mais, que poderia trazer novas questões sob uma outra perspectiva, um outro lugar de fala, reforçando ou mesmo contrariando as teses que estão sendo apresentadas.

Em relação à Cláudia Valli, identificamos que a descrição de seu dia-a-dia, aliada à transcrição de algumas de suas falas, opera na construção da imagem da mulher ocupada, preocupada, sobrecarregada, com preocupações que vão desde a saúde do filho até a própria aparência, como podemos perceber nos seguintes trechos:

Ela trabalha oito horas por dia e administra a casa onde mora com os três filhos - um casal de adolescentes, de seu primeiro casamento, e um menino de 9 anos, do segundo. Tem empregada apenas duas vezes por semana e uma ajuda "relativa" dos ex-maridos. Raramente dorme mais que quatro horas por noite, já que muitas vezes precisa adiantar trabalho de madrugada, além de monitorar o caçula, que é diabético. Na mesa de cabeceira da cama, uma pilha de livros comprados e não lidos. Na mente, a preocupação com os quilos a mais e a falta de tempo para fazer qualquer tipo de exercício. Claudia está sozinha desde a última separação, há cinco anos, e diz que um namorado, agora, seria mais um motivo de estresse. "A emancipação feminina é como um contrato que foi assinado sem ter sido lido direito e que agora precisa ser renegociado", diz ela. "A vida tornou-se um show que não pode parar." Antes de dar entrevista a ÉPOCA, Claudia passou no supermercado para comprar pão, leite e banana. Depois de feitas as fotografias, preocupou-se em não parecer mais velha do que é: "Dá para melhorar com Photoshop?". 
Essa "transformação" das falas individualizadas de Cláudia Valli, em falas que seriam as de várias mulheres, é reforçada no parágrafo seguinte, quando a redatora da matéria afirma: "longe de ser uma anomalia, a insatisfação de Cláudia com a própria vida é a mesma de milhões de outras mulheres mundo afora".

Logo adiante, essa insatisfação é relacionada à pesquisa sobre infelicidade feminina, que é apresentada nessa matéria. "O estudo, assim como Claudia, tende a enxergar no acúmulo de velhas tarefas e novas responsabilidades a causa dos dissabores femininos". Anteriormente, a citação da fala de Claudia sobre ser a emancipação feminina "um contrato que foi assinado sem ter sido lido direito e que agora precisa ser renegociado" também serve a esse propósito.

Cabe aqui comentarmos que não é explicitado como seria a renegociação de tal contrato e quais modificações objetivas poderiam ocorrer no cotidiano de Claudia Valli para que ela pudesse se sentir menos sobrecarregada e mais feliz.

Já Olga Torres, por sua vez, é apresentada como uma representante das "ambiguidades do mundo feminino". Essas "ambiguidades femininas", das quais Olga seria um exemplo, advêm de seu relato de ter sido casada e dona de casa em tempo integral por um período de dez anos, quando se sentiu infeliz, e de, já na época atual, se encontrar realizada no trabalho, mas sentindo falta de filhos e de uma família. A autora da reportagem acrescenta que Olga "admite" que as mulheres ainda não sabem o que fazer com tantas opções, trazendo ainda uma citação direta da fala de Olga: "a liberdade de escolha traz um peso enorme".

Entretanto, não chega a ser citado no texto a grande variedade de opções com as quais as mulheres não saberiam lidar. Considerando o exemplo de Olga, o que nos está sendo apresentado seria somente dois caminhos: estar casada, cuidando da casa e sentindo falta de trabalhar fora ou se sentir realizada no trabalho, mas sentindo falta de um companheiro e de uma família. No entanto, considerando outra das falas diretas de Olga: "Não quero um homem qualquer, mas alguém que seja companheiro e, desta vez, entenda que minha carreira é fator de realização"; o que parece ficar claro é o desejo por uma espécie de "terceira via", ou seja, a realização no trabalho junto a uma família e/ou a um parceiro amoroso que compreenda a importância da carreira como mais um fator de realização.

Podemos acrescentar também que a insatisfação vivenciada por Olga nas duas opções anteriormente apresentadas não invalida a possibilidade de que qualquer outra mulher possa encontrar sua felicidade em qualquer uma delas, sem necessariamente ter que conciliá-las e, isso, em nenhum momento, é citado por essa reportagem.
Para a criação do ethos discursivo da mulher contemporânea, identificamos que além dessa utilização de personagens da vida real, também são utilizados trechos de depoimentos de especialistas das áreas mais diversas, trechos de falas de mais duas mulheres selecionadas, estatísticas, tabelas numéricas e informações recolhidas de pesquisas e estudos citados na matéria jornalística. Trata-se de dados objetivos que funcionam como um apelo ao logos, ou seja, ao racional, mas que, ao mesmo tempo, atuam nessa constituição da imagem da mulher contemporânea, ou seja, um apelo ao ethos.

Essa utilização do logos operando na construção de um ethos, também pode ser encontrada na reportagem jornalística "O paradoxo da tristeza", veiculada pela revista Veja no mês de Abril do ano de 2010, também em versões impressa e digital.

Como já apontado anteriormente, ambas as reportagens são baseadas em uma pesquisa norte-americana cujo tema principal seria a queda nos níveis da felicidade feminina. $\mathrm{O}$ título da pesquisa não é citado em nenhum dos dois veículos. A revista Época refere-se a ela como "um estudo de Betsey Stevenson e Justin Wolfers, pesquisadores da Universidade da Pensilvânia, nos Estados Unidos" que mostra "um surpreendente e acentuado declínio da satisfação feminina nas últimas décadas". Já a matéria jornalística da revista Veja apresenta Stevenson e Wolfers como seus autores e cita esse mesmo aumento da infelicidade feminina em comparação à década de 1970 .

Ambas as matérias apresentam a tese paradoxal de que as condições da vida das mulheres ocidentais nunca estiveram melhores, enquanto os níveis de infelicidade só aumentam. Ambas também utilizam dados provenientes de outros estudos, além do de Stevenson e Wolfers. Ao analisá-las, identificamos algumas semelhanças e também algumas diferenças estruturais entre elas.

Ambas as matérias apontam e também refutam prováveis causas para a tal infelicidade generalizada. $\mathrm{Na}$ reportagem veiculada pela revista Época são citados:

- a questão da jornada dupla de trabalho (que é negada pela autora da reportagem);

- uma "extrema valorização da beleza e da juventude" afetando muito mais as mulheres que os homens;

- a multiplicação dos papéis femininos junto a um descompasso da forma como se veem e como gostariam de se ver;

- um refluxo da euforia da emancipação das décadas de 1970 e 1980;

- e um aumento das expectativas e das exigências.

Já na reportagem veiculada pela revista Veja são citadas:

- "mudanças na estrutura familiar e uma crescente desigualdade" (o que é logo descartado, já que a 
infelicidade estaria presente tanto entre casadas quanto em não-casadas);

- a obrigação de ir todos os dia para o trabalho e/ ou universidade (o que também é refutado, já que a insatisfação também atingiria donas de casa em tempo integral);

- "a hipótese do "segundo turno" de trabalho" ou jornada dupla de trabalho (que não é negada como na reportagem anterior, mas que é descartada como possível causa, uma vez que mulheres com filhos ou sem filhos, casadas ou não casadas apresentariam níveis idênticos de insatisfação);

- "declínio da satisfação das mulheres quanto a certos domínios da vida (emprego, finanças e casamento)", o que também pode ser relacionado com a multiplicação de papéis exercidos e um aumento das expectativas e exigências citados na reportagem da revista Época. Nesse caso, cada mulher se queixaria de um determinado domínio, o que abaixaria a média geral do tal índice mensurável de felicidade, sendo o domínio financeiro apontado pela reportagem como o mais problemático.

Chamou-nos a atenção que a questão da dupla jornada de trabalho feminino, por exemplo, é levantada nas duas reportagens. No entanto, enquanto essa reconhecida tese é reafirmada pelos autores da matéria da revista Veja, a autora da matéria da revista Época chega a negá-la, apresentando algumas estatísticas que indicariam uma proximidade (não equilíbrio ou igualdade) nas horas de serviços domésticos executados por homens e mulheres.

Outro ponto que identificamos é que as duas reportagens conseguem chegar a algumas conclusões parecidas, ou seja, a de que seria o aumento das exigências femininas (internas e externas) e a multiplicação de papéis exercidos as prováveis causas da insatisfação.

A reportagem veiculada pela revista Época, "Por que as mulheres são tão tristes?", segue, então, o caminho de se questionar se "os conservadores, que sempre atacaram o feminismo como antinatural teriam razão?" e se "mulheres seriam mais felizes se retornassem ao papel tradicional de mãe e esposa?". Apresentam ainda, em apoio a essa tese, alguns dados anglo-saxões sobre o desejo de "volta ao lar" por parte das mulheres.

O que consideramos problemático nesse tipo de argumentação é que ela parece não levar em conta que, por motivos econômicos, para a maioria das mulheres essa "volta ao lar" não é simplesmente uma questão de opção. As mulheres das classes econômicas mais baixas sempre tiveram que trabalhar, fosse no mercado informal ou formal e as lutas empreendidas nas últimas décadas diziam respeito não somente ao direito de trabalhar, mas também ao de obter salários iguais ao dos homens pelo mesmo ofício e por um ambiente de trabalho mais saudável, livre de assédio moral e/ou sexual, entre outras questões.

No entanto, após seguir esse direcionamento, a reportagem é finalizada com uma defesa da busca da independência, do equilíbrio dos papéis sociais e das expectativas, através de alguns trechos de citações diretas da jornalista norte-americana Leslie Bennets, autora de um livro denominado The Feminine Mistake (O erro feminino) como, por exemplo: "Ter uma família e trabalhar não dará um resultado perfeito, mas é o melhor que se pode ter".

Já a reportagem veiculada pela revista Veja, "O paradoxo da tristeza", é finalizada, apresentando outra conclusão: a de que talvez as mulheres, hoje, simplesmente se sintam mais confortáveis para expressar sentimentos de insatisfação do que antigamente e, também, reforçando que o fato de as mulheres poderem ser mais exigentes em relação à própria satisfação e felicidade não é algo necessariamente negativo, como podemos observar no penúltimo parágrafo da matéria:

As mulheres de hoje podem também esperar mais para si mesmas, e podem exigir mais para se satisfazer. $\mathrm{Na}$ década de 70, elas, ao avaliarem seu bem-estar, provavelmente se comparavam apenas a outras mulheres, enquanto as de hoje têm um grupo de referência diferente - que inclui os homens. Se for esse o caso, então o movimento feminista teve sucesso em uma das suas metas mais importantes: permitir que as mulheres acreditem que são tão capazes quanto os homens.

Em relação ao apelo ao pathos, consideramos que ambas as reportagens seguem um caminho parecido, ou seja, o de não recorrer explicitamente a alguma estratégia que possa ser classificada, principalmente, como um apelo ao pathos.

Consideramos, então, que se trata de duas reportagens jornalísticas "tradicionais", que, habitualmente, buscam a persuasão de seu auditório através de dados objetivos que indicam um apelo mais significativo ao logos.

No entanto, como visto anteriormente, levando em conta a relação intrínseca entre os três meios de persuasão, nada impede que uma estratégia argumentativa, que pareça visar o apelo ao logos, por exemplo, possa acabar suscitando alguma emoção no auditório, configurando, assim, um apelo ao pathos. Da mesma forma, a menção à infelicidade da mulher contemporânea, sustentada por dados do logos, vincula-se também ao ethos e, em virtude de se tratar de um ethos de infelicidade, relaciona-se também a um apelo ao pathos.

Por outro lado, cumpre lembrar, com Galinari, que, no caso em análise, o ethos de infelicidade refere-se 
ao ethos de outrem, ao ethos discursivo das mulheres contemporâneas e não ao ethos do autor da reportagem.

Um último recurso que citaremos e que é também utilizado por ambas as reportagens é a utilização de imagens. A reportagem veiculada pela revista Época mostra fotos de suas personagens "Cláudia Valli" e "Olga Torres" que podem ser vinculadas tanto a um apelo ao logos (por ser uma demonstração da existência das "personagens"), quanto ao ethos (já que auxiliam na construção da imagem da mulher por parte do auditório) e quanto ao pathos (já que as expressões de tristeza apresentadas por ambas podem suscitar diversas emoções no auditório, além de corroborarem com a construção do ethos da mulher infeliz).

Já a reportagem veiculada pela revista Época optou por utilizar fotos mais "artísticas" de duas modelos desconhecidas, ambas submersas, também com expressões de tristeza, sendo que a primeira ainda apresenta os pulsos amarrados. Tais imagens podem nos remeter a uma metáfora de uma mulher contemporânea privada de liberdade, que está se afogando em meio às dificuldades, sem conseguir sequer respirar. Essa metáfora tanto pode auxiliar na construção de um ethos da mulher quanto pode apelar ao pathos do auditório.

Consideramos então que, no caso das duas reportagens jornalísticas analisadas, as várias estratégias utilizadas já apontadas anteriormente, como a utilização de imagens, a descrição do dia a dia das entrevistadas, as transcrições de depoimentos de especialistas acerca do comportamento da mulher contemporânea e os vários estudos e estatísticas citados, podem tanto significar um apelo ao ethos (na criação da imagem da mulher contemporânea), quanto ao logos (no apelo ao racional do auditório) e quanto ao pathos, na medida em que podem suscitar no auditório as reações mais diversas, como indignação, simpatia, tristeza, identificação, piedade, enfim, seja em relação aos dados apresentados, seja em relação a própria criação da imagem da mulher contemporânea que é realizada.

\section{Considerações finais}

Neste artigo, tivemos por objetivo realizar uma análise retórico-argumentativa das reportagens jornalísticas "Por que as mulheres são tão tristes?" " "O paradoxo da tristeza" veiculadas pelas revistas Época e Veja, respectivamente.

Utilizando as três provas aristotélicas - ethos, pathos e logos - buscamos identificar se as estratégias argumentativas utilizadas em ambas as matérias midiáticas propiciaram ou não um ethos discursivo da mulher contemporânea que contivesse elementos em comum ao backlash, tal como conceituado por Faludi (1991) e caracterizado na primeira parte desse artigo.
Após as análises consideramos que, na primeira reportagem, através da estratégia da "criação de personagens" e de toda sua construção argumentativa, surge um ethos discursivo de mulher contemporânea bastante próximo ao que é criado pelo backlash, ou seja, o de mulher totalmente emancipada, mas extremamente infeliz, cuja infelicidade vem a ser causada exatamente por conta dessa "emancipação". O último parágrafo, que encerra a reportagem defendendo a independência financeira e a busca por um equilíbrio entre vida pessoal e profissional, não contradiz essa tese que é construída anteriormente.

Já na segunda reportagem analisada, consideramos que, ainda que seja criado um ethos discursivo de mulher infeliz, a reportagem toma um rumo diverso ao do backlash e ao da reportagem anterior, uma vez que defende a melhoria das condições de vida do sujeito feminino, em geral, sem colocar a igualdade de oportunidades e direitos como algo negativo.

\section{Referências}

AMOSSY, Ruth (Org.). Imagens de si no discurso. São Paulo: Contexto, 2005.

AMOSSY, Ruth. Argumentação e análise do discurso. Perspectivas teóricas e recortes disciplinares. EID\&A-Revista Eletrônica de Estudos Integrados em Discurso e Argumentação, Ilhéus, n. 1, p. 129-144, nov. 2011.

ARISTÓTELES. Retórica. Lisboa: Imprensa Nacional Casa da Moeda, 2005.

BEAUVOIR, Simone de. O segundo sexo. Fatos e mitos. São Paulo: Difusão Européia do Livro, 1970.

CÍCERO. De oratore. Cambridge: Harvard University Press, 1942.

CHARAUDEAU, Patrick. Discurso político. São Paulo: Contexto, 2008.

DEL PRIORE, Mary. História das mulheres no Brasil. São Paulo: Contexto, 2004.

FALUDI, Susan. Backlash: contra-ataque na guerra não declarada contra as mulheres. Rio de Janeiro: Rocco, 2001.

GALINARI, Melliandro. Sobre ethos e AD: tour teórico, críticas, terminologias. Delta - Documentação de Estudos em Linguística Teórica e Aplicada, São Paulo, v. 28, n. 1, 2012.

GALINARI, Melliandro. Logos, ethos e pathos: "três lados" da mesma moeda. Alfa - Revista de Linguística, São Paulo, v. 58, n. 2, p. 257-285, 2014.

ISÓCRATES. Antidosis. London: William Heinemann, 1980.

MENDES, Eliana. A Produção textual: Revitalizando a pedagogia retórica. Tese de Titular inédita - UFMG, Belo Horizonte, 2010

PERROT, Michelle. Minha história das mulheres. São Paulo: Contexto, 2007.

PLATÃO. Phaedrus. London: Harvard University Press, 2005. 
REBOUL, Olivier. Introdução à Retórica. São Paulo: Martins Fontes, 2004.

REVISTA ÉPOCA. Por que as mulheres são tão tristes? Disponível em: <http://revistaepoca.globo.com/Revista/ Epoca/0,EMI98917-15228,00-POR+QUE+AS+MULHERES +SAO+TAO+TRISTES.html>. Acesso em: 10 maio 2018.

REVISTA VEJA. O paradoxo da tristeza. Disponível em: $<$ http://users.nber.org/ bstevens/press\%20reaction/Paradox
$\% 20$ of $\% 20$ Declining $\% 20$ Female $\% 20$ Happiness/MulherVEJAEdicaoEspecial.pdf>. Acesso em> 10 maio 2018.

Recebido: 31/05/2018

Aprovado: 10/07/2018

(D) ELAINE CRISTINA FONSECA <elainecrisnl@yahoo.com.br>

Doutoranda, Universidade Federal de Minas Gerais, Belo Horizonte, Minas Gerais, Brasil. 